\title{
Kandinsky: Una mirada desde el presente
}

\author{
Alfonso Castrillón Vizcarra
}

El título de este artículo es quizá una paráfrasis de "Mirada retrospectiva", segundo libro de Wassily Kandinsky, pero a diferencia de su evocación nostálgica quisiera aproximarme al pintor desde la perspectiva de quien escribe desde el presente y que, por lo tanto, no puede dejar de lado su circunstancia. Mi mirada es pues parcializada, después de haber revisado la obra escrita de Kandinsky que me ha permitido, sin embargo, tomar frente a él una posición definida.

Antes de entrar en el tema habría que resolver, sin embargo, algunas cuestiones previas y la primera en

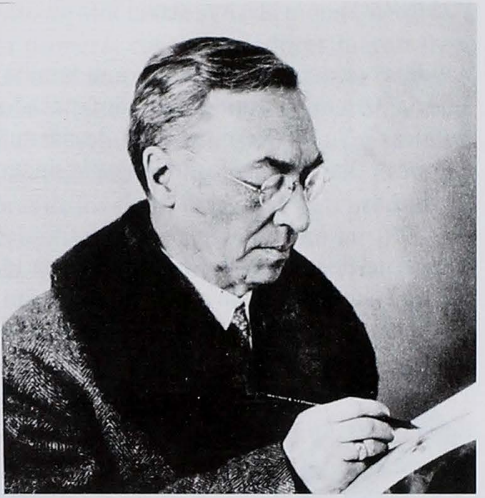

Wassily Kandinsky, 1866-1944 relación a la pregunta que con seguridad se habrá hecho el lector: ¿qué hace Kandisnky en una lista de pintores alemanes?' Kandinsky nace en Moscú en 1866 y vive en Rusia en total 37 años, pero residió en el extranjero 40, 25 de los cuales pasó en Alemania, hasta el punto de decir que era su segunda patria.

En una carta a Gabriela Münter (1904) le dice: "Me crié a medias alemán: mi primera

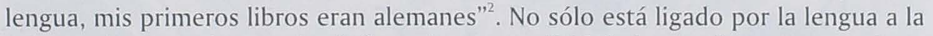
cultura alemana, sino por las influencias que recibió de los intelectuales y artistas alemanes a su llegada a Munich y los tres libros que escribió Kandinsky sólo pudieron haber nacido en Alemania, el primero en la huella del modernismo y el segundo bajo los efectos de funcionalismo de la Bauhaus. Todas estás razones, a las que deben sumarse la influencia que él tuvo en los movimientos artísticos "Nueva Asociación de Artistas" y el "Jinete azul", lo acreditan como artista inscrito en el marco de la cultura alemana.

En principio el texto fue leído en el ciclo "Introducción a la pintura alemana", organizado por David Sobrevilla, el Goethe Institut y la Municipalidad de Miraflores en 1979.

Carta a Gabriela Münter. "Mirada retrospectiva", Emecé Editores, Bs. As, 1979. 
El segundo punto que debemos resolver es si podemos reconstruir la historia de Kandinsky ya que él se presentó deshistorizado en su libro "Mirada Restrospectiva", en un juego de "racconti" que lo hacen inasible. Es cierto que nunca podremos reconstruir la verdadera historia de una persona y menos de un ser tan complejo como Kandisnky. Pero recurrir a ciertas fechas, fijar su actividad en un determinado tiempo y espacio, nos da la posibilidad de recuperar al hombre diluido en una autobiografia casi mítica, donde no hay noción clara del presente y del pasado.

El tercer punto previo tiene que ver con el carácter dual del artista Kandinsky: se lo estudia sólo como pintor sin tener en cuenta sus textos, que se inscriben en la teoría general de la cultura de su época. Pienso que Kandinsky es un pintor-escritor, una unidad compuesta de dos partes inseparables: la teoría y la práctica.

\section{LOS INICIOS}

Kandinsky nace en el seno de una familia acomodada, cuyo jefe era oriundo de la Siberia Oriental, donde "sus antepasados habían sido deportados por razones políticas". Su madre moscovita de nacimiento, reunía en su persona "una belleza exterior" llamativa y una energía inagotable según declaraciones del propio Kandinsky.

Los recuerdos infantiles se remontan a los tres años, cuando sus padres lo llevan consigo a un largo viaje por Italia y lo dejan por un tiempo en un jardín de infantes en Florencia. Luego regresan a Moscú, cuando tenía cinco años, pero la familia tiene que

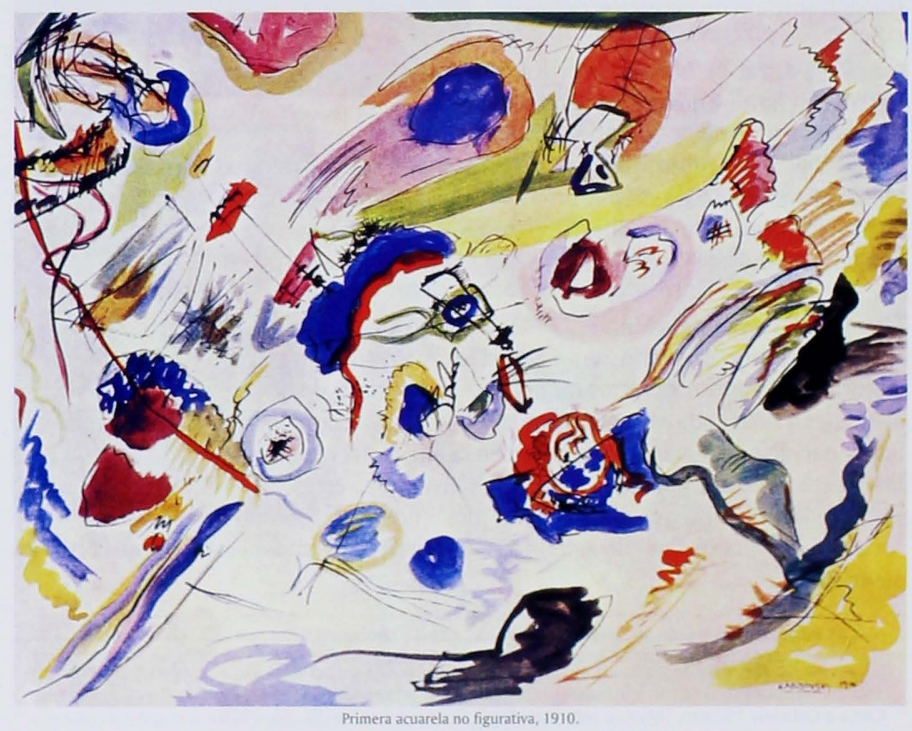


trasladarse a Odessa, a causa de la salud del padre. En esta ciudad del sur de Rusia, donde realiza Kandinsky sus estudios secundarios, se siente como un huésped extraño. Sólo a los dieciocho años se instala nuevamente en Moscú, donde sigue estudios de Economía Política y Derecho en la Universidad de esa ciudad. Ahí se quedará hasta los treinta años.

Tuvo la oportunidad de conocer de cerca el desarrollo cultural ruso, que se caracterizaba en ese momento por una vuelta a las fuentes de inspiración nacional. En relación a la pintura, ese espíritu encontró su expresión en el arte de Vrubel (18561911). Las ideas de la renovación eslava hicieron posible la profundización de los estudios históricos y en pintura el descubrimiento del medioevo ruso.

Son dos los hechos importantes que prepararon el camino a la vanguardia rusa: la creación en 1870 de la "Sociedad de exposiciones ambulantes" apoyada por el mecenas moscovita Tretiakov y el nacimiento de MIR ISKUTSVA ("El mundo del arte"), fundado en San Petersburgo en 1890. La primera, cuyos fundadores fueron trece alumnos de la academia de Bellas Artes que rechazaron el tema "Odin en la Walhalla" para el examen final, tuvo gran importancia ya que su programa se proponía hacer participar al pueblo todo en la vida artística. El segundo, Mir Istkustva, fue fundado por Sergei Diaghilev, que más tarde se hará conocido por los ballets rusos. La revista que editaron se encargó de difundir las obras de los simbolistas rusos y reproducir las obras de los impresionistas y post impresionistas. Diaghilev presentó en 1898 una gran exposición internacional que hizo ver a los rusos, en vivo, la pintura impresionista francesa.

El tema del Impresionismo nos lleva directamente a una experiencia que marcó la vida de Kandisnsky: visitando la exposición de los impresionistas franceses en Moscú se encontró delante de una pintura que representaba una parva de heno, como podía leer en el catálogo, pero que no pudo reconocer.

Otro hecho que revelará a Kandinsky las posibilidades de un lenguaje pictórico, fue la audición de "Lohengrin" de Richard Wagner. "Mentalmente -dice Kandinsky- veía todos mis colores, los tenía antes mis ojos". El acercamiento de la pintura con la música que le sugirió esta experiencia se convertirá con el tiempo en un matrimonio indisoluble, donde cada color transcribirá una sonoridad en el código creado por el pintor.

En relación a su sensibilidad pictórica en formación, tampoco hay que olvidar la experiencia que vivió Kandinsky con motivo de un viaje al gobierno de Vologda. Cuando llegó a esta localidad perdida, al norte de Rusia, y entró en una isba (casa campesina), nos dice: "En esas casas mágicas experimenté algo que no volvió a repetirse después. Esas casas me enseñaron a moverme en el seno mismo del cuadro a vivir dentro del cuadro" ${ }^{\text {. }}$ 


\section{II.- ALEMANIA. MUNICH.}

En la autobiografía de Kandinsky la llegada a Munich aparece mitificada a través de la figura del caballo. En los párrafos anteriores de su relato ha hablado de un juego de caballitos en Italia, donde había uno pío que le producía gran alegría. Pero el tiempo se adelgaza, se vuelve irreal, salta a la época de su aprendizaje y se enlaza con otro episodio: la llegada a Munich donde se encuentra, como una aparición en primavera, con el caballo pío en las calles de la ciudad bávara. La parte que cela poéticamente es la cruda realidad: Aquí comienza su aprendizaje con Antón Azbe, quien lo enfrenta al trabajo con modelos. Pero los modelos desnudos le repugnan. También su postulación a la Academia que termina en fracaso. Cambio de maestro: esta vez Franz Stuck es quien lo somete a la dura disciplina de trabajar sólo en blanco y negro.

Creo que resultaría interesante echar una mirada a las corrientes pictóricas alemanas que Kansinsly encuentra ya desarrolladas a su llegada. Las dos más importantes eran, la realista, encarnada en Leibl (1844-1900) y la idealista representada por Boecklin (1827-1901).

También hay que tener en cuenta, dentro del mismo proceso, la importancia que tuvo la pintura impresionista en Alemania y su influencia en artistas como Libermann (1847-1935) que estudió en París; Slevogt (1868-1932) y Corinth (1858-1925). Pero, como señala Dora Valier, "la sensación fugaz que buscan los impresionistas es extraña a la sensibilidad alemana" y se vuelve más hacia los contenidos que eclosionarán en el expresionismo.

Libermann será el principal promotor de la Secesión berlinesa que se convertirá en el bastión del arte moderno. Allí expondrán Slevogt y Corinth y en 1901 se darán a conocer cinco cuadros de Van Gogh, y más adelante una serie de cuadros Nabis. Desprovista la Secesión berlinesa de una verdadera fuerza de renovación contribuirá, sin embargo, a formar el gusto del público y familiarizarlo con el arte del resto de Europa.

Este es el panorama que encuentra Kandinsky cuando llega a Munich. Es comprensible que desde el principio de su aprendizaje sintiera un oculto rechazo, primero hacia el realismo (como demuestra en el episodio de los modelos) y segundo hacia los contenidos en la pintura, que lo llevarán, poco a poco, a la conceptualización del arte abstracto.

En 1906 Kandinsky está todo el año en París, en el momento del triunfo fauvista y de este contacto, su paleta se hará más radiante e intensa. Kandinsky construye su cuadro con color, procediendo por superposición de tonos o mezclándolos en la paleta. "Su gama es insólita y la pasta lujuriosa". En esa espesa capa de pintura, la pincelada se hace progresivamente alargada y rápida. Estas obras de París preparan el camino de la serie de Murneau, pueblito cercano a Munich, donde Kandinsky pinta entre 1908 y 1909. "En estas series los colores desbordan los límites de los objetos figurados" hasta hacerlos casi irreconocibles ${ }^{4}$.

Valier, Dora. L'Art abstrait. Librairie Generale Francaise, 1967, p.66. 


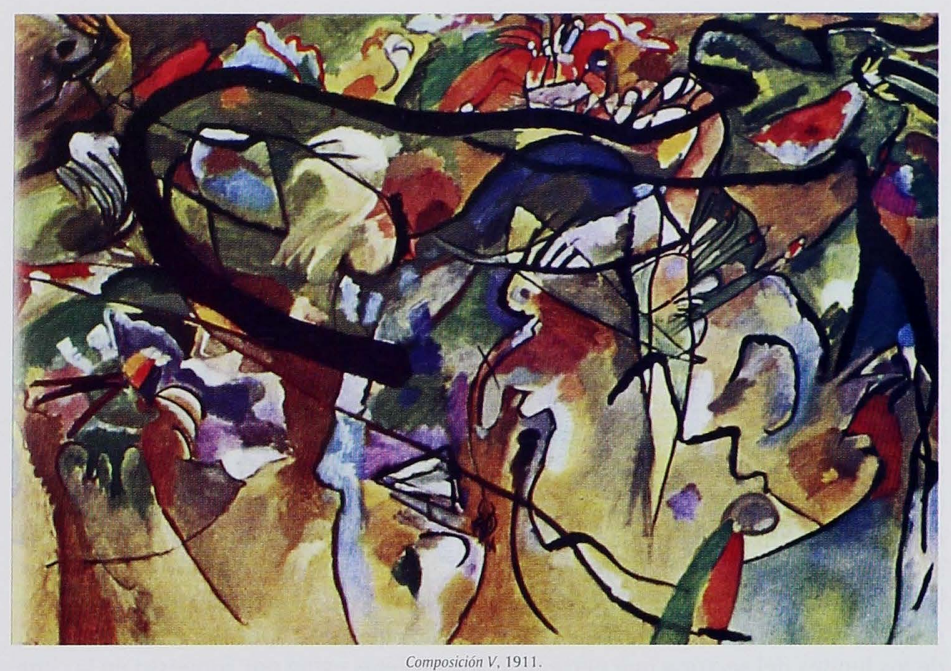

La entrada al tema del abstracto se hace también a través del mito en "La mirada retrospectiva". Como es un paso trascendental en su vida, necesita del aura del milagro, que ocurre según propias palabras, un día que regresaba a su casa, luego de haber pintado en el campo, a la hora del crepúsculo. La escena está preparada: entra y ve "un cuadro de una belleza indescriptible, impregnado de un vigoroso ardor interior. Al principio me quedé paralizado, pero en seguida me dirigí rápidamente hacia ese cuadro misterioso (en el cual sólo veía formas y colores y cuyo tema era incompresible). Era uno de mis cuadros puesto a un lado y apoyado sobre la pared".

En esta época densa de acontecimientos, como la fundación con Jawlensky de la Nueva Asociación de Artistas, de corta duración (1909); la creación de la primera acuarela abstracta de Kandinsky en 1910 o la creación, con Franz Marc, de Bleue Reiter (1911), la obra más importante de Kandinsky es su construcción teórica para justificar, en un medio adverso, el advenimiento de la pintura abstracta. "De lo espiritual en el arte" se llama el libro que escribió en 1910, pero que sólo publicó en 1912. Como es una obra importante merece que la comentemos, aunque sea sucintamente.

\section{DE LO ESPIRITUAL EN ELARTE}

El texto de Kandinsky se propone dos objetivos que cumple a cabalidad:

a) Inserir el arte abstracto (no figurativo) en la cultura de su época y darle categoría estética.

"Mirada...", p. 110. 
b) Explicar al lector la actitud del pintor frente a sus medios de expresión abstractos, el lenguaje de las formas y colores.

Una cualidad que sin duda hay que reconocer en Kandinsky como escritor, es la claridad de sus objetivos y el efecto que quiere despertar en sus lectores, por lo tanto su inteligencia discursiva para conseguirlos. Para esto presenta, en la introducción, un panorama bastante pesimista y sombrío de la sociedad en que vive; nada mejor para su propuesta que este telón de fondo para que ella se destaque: la sombra hace más viva la luz. "Después del largo período de materialismo del que comienza a despertar, nuestro espíritu está lleno de gérmenes de desesperación e incredulidad, pronto a hundirse en la nada. La abrumadora opresión de las doctrinas materialistas, que han convertido la vida del universo en una detestable broma, no se ha disipado todavía",

Sin embargo Kandinsky se esfuerza en demostrar que la vida espiritual ha retomado las riendas de la cultura de Occidente y que se presenta hoy con más fuerza que ayer; a esta vida espiritual, fuerte y sana, pertenece el arte. Para hacer comprender cómo el arte sigue una línea ascendente, se vale de la figura del triángulo: los artistas de la base son los que utilizan su genio para halagar necesidades inferiores, para los cuales sólo cuentan los bienes materiales; pero aquellos que son capaces de mirar más allá de los límites del sector a que pertenece, los profetas están por supuesto en la cima del triángulo, en la parte más destacada. La figura de Moisés descendiendo de la montaña que entrega a los hombres la fórmula de la sabiduría, es el mismo Kandinsky portador del nuevo lenguaje.

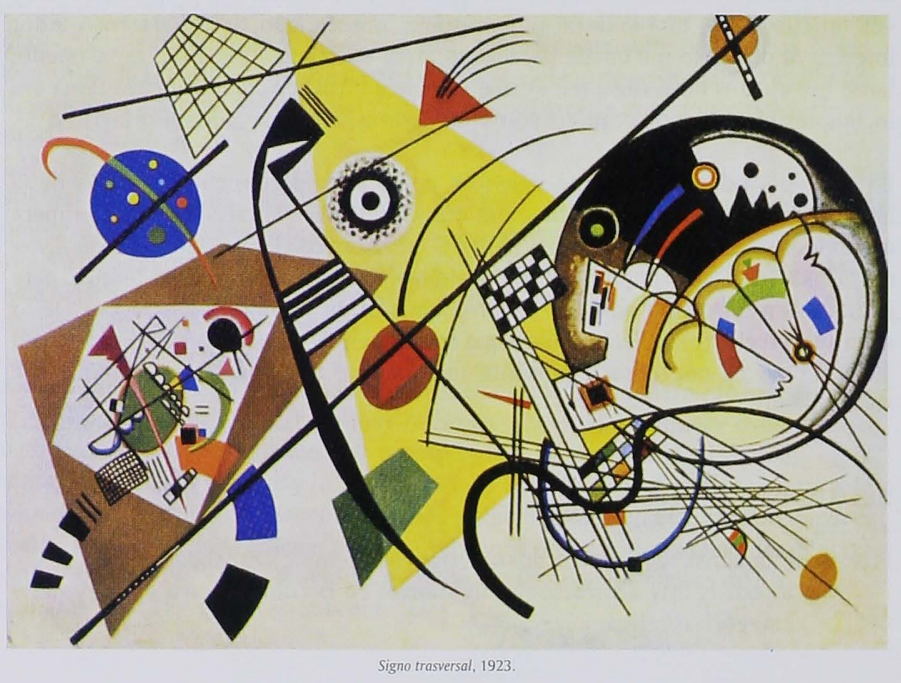

"De lo espiritual en el Arte", Ediciones Nueva Visión, 4ta. edición, 1967, p.12. 
El tercer capítulo tiene un tono apocalíptico todavía más fuerte: "El cielo se halla vacío. Dios ha muerto"; las palabras que siguen están llenas de temor y horror. Es curioso comprobar cómo junto a estas palabras aparezcan alusiones a la política, al socialismo y al capitalismo que indican su aversión a las contingencias sociales. Toda esa situación lo lleva a detectar el miedo en los otros, "el miedo a lo desconocido" que los paraliza, pero que en el fondo no es más que su miedo a que la cultura se desvíe por otro camino. En medio de su "aristocracia de la sensibilidad", elitista y exclusiva, le resulta molesto la movilidad social que hace posible el ascenso de otros hombres, los profesionales, los especialistas?

El positivismo y el materialismo enervan a Kandinsky pero un "verdadero sabio que escruta la materia" hasta ponerla en duda, eso lo llena de entusiasmo, porque cree que la electricidad dinámica reemplazará íntegramente la materia ${ }^{8}$. Eso es, desintegrar la materia fastidiosa y lastrante que nos apega a la tierra y no nos deja ascender.

El paso a la explicación teosófica es pues lógico. Las páginas de este capítulo que comenzó tenebroso y pesimista, se presenta aquí radiante, gracias a las teorías de Madame Blawatsky: "en el siglo XXI la tierra será un paraíso en comparación con lo que es hoy".

Frente a los artistas materialistas están los aristócratas del espíritu: Maeterlink, de quien procede la preocupación kandinskiana del sonido interior; Wagner, Debussy, Scriabin, Dante Gabriel Rossetti, Boecklin, Stuck, Segantini, larga lista de artistas de procedencia romántica, post romántica y simbolista, de tendencias más bien crepusculares, portaestandartes de un arte finisecular, tipo Secesión, que no tienen que ver con el golpe seco y radical que significó la no figuración. Hay sin embargo tres nombres que sobresalen con luz propia en la lista de Kandinsky: Schoenberg, Cézanne y Picasso.

A Kandinsky no le interesa la revolución sonora, física, que había emprendido el primero con la ruptura de la tonalidad. Lo explica diciendo: "cuando se ha renunciado a las formas convencionales de lo bello, una necesidad interior nos impele hacia "lo bello interior". "Su música nos hace penetrar en un reino nuevo, en donde las emociones musicales no son totalmente auditivas, sino, ante todo, interiores." ${ }^{\text {. Lo }}$ bello interior suple la propuesta revolucionaria de una nueva armonía.

Kandinsky convierte a Cézanne en un animador de naturalezas muertas: "De una taza de té ha hecho un ser dotado de alma". Sabemos, sin embargo, que al pintor de Aix en Provence no le preocuparon estas supercherías.

La apreciación que hace de Picasso es por demás mistificadora: resulta que el español es un Proteo volatinero que deja espantados a sus imitadores. A Kandinsky le interesa destacar cómo Picasso destruye, a fuerza de lógica, los "elementos materiales, no por 
disolución, sino por fragmentación". Parece asombroso -concluye- que, al proceder así, se intente, sin embargo, conservar la apariencia material" ${ }^{\prime \prime}$. Todo esto, como es fácil comprender, a favor de su tesis teosófica.

En el pequeño capítulo IV, y con la preparación de los anteriores, Kandinsky puede abordar el problema del arte no figurativo, que es su más íntima preocupación. La tendencia al "no realismo", al abstracto, es la esencia interior ${ }^{12}$ y como la música, según la tradición, es "la más inmaterial de las artes" le resulta a Kandinsky una buena socia de la pintura: "Desde hace siglos, la música es por excelencia el arte que expresa la vida espiritual del artista"13. En resumen: el artista que aspire a la "esencia interior" no se contentará con imitar la naturaleza, tiene que inventarla desde adentro, desde la abstracción misma.

El espiritualista Kandinsky cae en la cuenta de que, paradójicamente, el alma tiene atributos "sensoriales", que "gusta" como un gourmet ante un manjar ${ }^{14}$, se "abre" o se cierra, como si fuera un molusco excitado. Para desechar cualquier sospecha de materialismo hasta las sensaciones son mistificadas por este alquimista del espíritu: su teoría de los colores, por lo tanto, no se basa en las leyes físicas estudiadas por Chevreul o Rood, sino en una interpretación simbolista del fenómeno colorístico. "Los colores claros atraen mucho más el ojo y lo retienen. Los colores claros y cálidos lo retienen aún más; así como la llama atrae al hombre irresistiblemente, el bermellón atrae e irrita la mirada. El amarillo limón vivo hiere los ojos. El rojo no puede tolerarlo. Parece el sonido agrio de una trompeta, capaz de destrozar un oído. Los ojos pestañean, $y$ la mirada va a sumergirse en las calmas profundas del azul y del verde ${ }^{\prime \prime 15}$. Respecto al amarillo agrega en otra parte: "El amarillo tiene un efecto perturbador, pica, excita e importuna con una especie de insolencia insoportable"16.

Pero no todos pueden llegar a la práctica de este código, "sólo el individuo altamente evolucionado", que tiene el alma abierta a toda las impresiones y que posee una gran sensibilidad afinada, como esos viejos violines que vibran al menor toque ${ }^{17}$.

En este recorrido hacia el mundo interior, le toca el turno a la forma en el capítulo VI. Kandinsky sigue en este caso las ideas de los teóricos de la "visibilidad pura" es decir Hans von Marees y Honrad Fiedler, quienes siguiendo a su vez a la tradición alemana que viene de Kant, separan la forma del contenido, para hacer de ella el motivo de una nueva ciencia, la ciencia del arte, que no tiene que ver con la literatura, la moral o la religión. "La forma, en tanto que representación del objeto (real o no real), en tanto que delimitación puramente abstracta de un espacio o de una superficie, puede existir sola"18. La forma "es un ser espiritual" y hasta emana un perfume propio, pero aparte de estas consideraciones subjetivas, la forma puede exaltar o atenuar el efecto de los colores: "los colores 'agudos' hacen valer mejor sus cualidades en una forma

\footnotetext{
Op. cit. p. 39.

Op. cit. p. 40.

Ibidem.

"Op. cit. p. 45.

Op. cit. pp. 46,47

${ }^{16}$ Op. cit. p. 73

17 Op. cit. p. 48

Op. cit. p 52
} 
puntiaguda"19. Y así Kandinsky da rienda suelta a la imaginación al punto de perder el sentido de la realidad y convertir sus experiencias personales en generalizaciones para el resto de sus lectores. Algún interlocutor ficticio pudo decirle: "Pero ¿y qué hay de lo humano, que hay del 'sentido' y la comunicación?” Y Kandinsky, como si le respondiera: "el artista que sigue el camino del abstracto, al excluir la figuración, puede sentirse privado de lo más humano que tiene; pero, al mismo tiempo la forma abstracta, cuando se la emplea con exclusión de cualquier otra, cuando es experimentada como una forma neta, precisa, bien definida, la aparente pobreza se cambia en enriquecimiento interior" ${ }^{20}$. Todo es tan relativo que, con justeza, se puede decir que al fin todo depende del ojo que mira, ya que detrás están un cerebro, un pensamiento, una cultura, etc. etc.

No podemos extendernos demasiado en este examen del primer libro de Kandinsky; añadir sólo que el espiritualismo de Kandinsky lo lleva de la "necesidad del arte", al contenido místico del arte: el artista tiene que estar atento a la voz de su "necesidad interior", porque los procedimientos son sagrados si son interiormente sentidos, de lo contrario constituyen pecado ${ }^{21}$. No podía faltar, en el proceso creativo que sigue Kandinsky, el sentido de culpa ligado al arte, que se arrastra desde el Medioevo y cuyos tratadistas consideraban como necessitas, consecuencia del pecado original. No puede llamarnos la atención que, para superar esta culpa, el pintor se entregue a la Teosofía, esta ascesis espiritual por la cual el alma se va despojando del lastre terreno, para unirse definitivamente con Dios. "De lo espiritual..." se cierra con una frase reveladora: "Este nuevo espíritu de la pintura se halla orgánica y directamente asociado al próximo advenimiento del Reino del Espíritu; él será el alma de la época de la Gran Espiritualidad"22.

Es en el clima espiritualista y teosófico de "De lo espiritual..." que nace la segunda asociación de pintores fundada por Kandinsky y Franz Marc: Der blaue Reiter (El Jinete Azul) en 1911. Exposiciones: dos; una en la galería Tanhauser, en 1911 y otra, en la galería Goltz, en 1912. Expositores: A. Macke, Campendonk, Enstein, Braue, Klee, Kubin, Malevich, Larionov y Arnold Shoenberg. ¿Cuál es su estética? Quien haya leído "De lo espiritual..." comprenderá los ideales del El Jinete Azul. Una comparación con sus colegas expresionistas de El Puente, creado en 1905, los caracterizará plenamente. "El Jinete Azul -dice De Micheli ${ }^{23}$ - tendía a la purificación de los instintos antes que a su desencadenamiento sobre la tela; no buscaba un contacto fisiológico con lo primordial, sino un modo de coger la esencia espiritual de la realidad".

Esta experiencia concluye en 1914, el año fatídico de la guerra, y la sobrexcitada sensibilidad de estos hombres termina ofendida y golpeada por la brutalidad bélica. Bien lo había dicho Madame Blavatzky, "el siglo XXI será un siglo de paz". Pero no el presente que vivió Kandinsky.

\footnotetext{
${ }^{19}$ Op. cit. p. 54

${ }^{20}$ Op. cit. p. 56

${ }^{21}$ Op. cit. p. 66

Op. cit. p. 115

${ }^{29}$ De Micheli, Las vanguardias artísticas del siglo XX. Alianza Forma, Madrid, 1983, p. 100.
} 


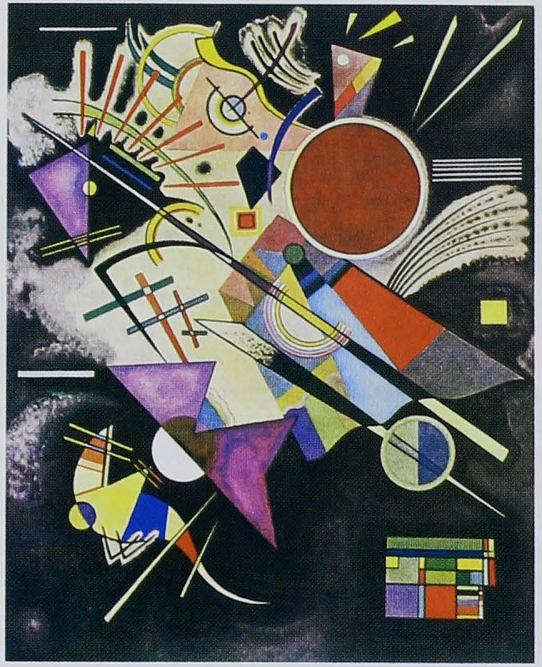

Acompañamiento negro, 1924.
V.- REGRESO A LA PATRIA

En 1914, Kandinsky deja Alemania y llega a Moscú. Pero ¿qué ha pasado mientras tanto en Rusia? También allí, como en París o Munich hubo una gran efervescencia cultural en los primeros años del siglo. En 1910 se organizan dos grupos, uno en San Petersburgo, "La unión de la juventud", donde figuran Philonov, Rozanova, Chkolnik, y otro en Moscú, "La Sota de oro" con Larionov (su creador), Gontcharova, Burliuk, Exter y Kulbine. En 1911, bajo la influencia de Burliuk, el grupo "La Sota de oro" organiza una exposición, donde figuran al lado de las obras de los pintores rusos Kandinsky, Kuprine y

Exter, los cuadros de Picasso, Léger y Le Fauconnier. Luego de separarse de "La Sota de oro", Larionov funda otro grupo "La cola del asno", que expone casi paralelamente con el primero, pero para el público de entonces estos grupos fueron iguales y los llamaban simplemente "futuristas". A partir de 1913, sin embargo, se volvieron decididamente hostiles.

En marzo de 1913 tuvo lugar en Moscú la muestra "Le cible" (El blanco) donde Larionov expone sus pinturas rayonistas y Malevich las suyas cubofuturistas. El 13 de octubre de 1913 se llevó a cabo la primera soirèe futurista donde se reveló Maiakovsky.

Este es el ambiente agitado que encuentra el futurista Marinetti, a fines de enero de 1914, cuando invitado por el círculo artístico y literario, dio tres conferencias en Moscú y dos en San Petersburgo. Pero la visita de Marinetti a Rusia forma parte de otra historia que aquí no tiene lugar.

Lo que se sabe de Kandinsky en Rusia entre 1914 y 22, puede resumirse de la siguiente manera: Kandinsky deja Alemania y pasa primero por Suiza y los Balcanes, hasta que llega a Rusia a fines de 1914. En diciembre de 1915 viaja con su familia a Estocolmo donde permanece hasta marzo de 1916. Según Dora Valier, Kandinsky llega a Rusia traumado por la guerra, a tal punto que en su diario anota en 1915 "ningún cuadro". En febrero de 1917, ya divorciado de la Münter, se casa con Nina Andreievskaia, con la que viaja a Finlandia. Sólo en 1918 comienza un período de intensa actividad ${ }^{24}$ : Es nombrado miembro del Departamento de Bellas Artes del Comisariado de Instrucción Pública, forma parte de la Oficina Internacional y del

Para este período ver el resumen biográfico que se publica en "Mirada..." Op cit. p. 81. 
Directorio de la sección Teatro y Cinematografía y además, director de la publicación "Iskusstvo". En 1919 trabaja en la Fundación del Museo de Cultura Pictórica de Moscú y en la Organización de los Museos de Provincia. Pero las contradicciones se siguen unas tras otras: en el proyecto de organización de los museos Kandinsky propone abandonar el orden cronológico para presentar las obras por categorías formales y cuando tuvo que discutir su programa concreto del INJUK (Instituto de Cultura Artística), donde tenía que vérselas con hombres y objetos del mundo real y no con líneas y colores puros, la situación se hizo insostenible para él. Fue precisamente entonces, cuando se publicó el manifestó productivista de Tatlin en diciembre de 1921, que Kandinsky abandona Rusia.

\section{VI.- NUEVAMENTE ALEMANIA}

Ya en Alemania en 1922, Kandinsky se integra inmediatamente al grupo de profesores de la Bauhaus de Weimar, donde trabajará hasta su disolución en 1933. Se inicia pues una etapa nueva para Kandinsky, que, después de su experiencia rusa, dará sus resultados en la metodología que pone en práctica en la escuela alemana y en su tercer libro "Punto y Línea sobre el plano"(1923).

"Punto y línea..." sólo podría haberse hecho realidad en la práctica de la Bauhaus. El tono de este libro es diferente al lirismo espiritualista de su primera obra, ya comentada. En "Punto y línea..." el lenguaje es preciso, escueto y Kandinsky asume una actitud cientifista que lo hace desear "la posibilidad de formular leyes con respecto al desarrollo humano en general" 25 . Kandinsky sigue creyendo, como los teóricos de la "visibilidad pura", en una ciencia artística. Propone analizar los elementos de la composición para lograr dos objetivos:

a) Los requerimientos de la ciencia en general, que nacen del impulso del saber (la ciencia pura).

b) Los requerimientos de la ciencia práctica ${ }^{26}$, pero también la familiaridad con el funcionalismo de la Bauhaus.

Sus comentarios sobre los elementos geométricos se convierten en una geometría poética, sobre todo cuando habla del "sonido absoluto de los ángulos" y las "trisonancias" logradas. No podemos negarle ingenio cuando caracteriza al punto: "El punto geométrico encuentra su forma material en la escritura: pertenece al lenguaje y significa silencio"27.

El trabajo de Kandisnky es pues la culminación de una serie de investigaciones sobre la simbología de las formas y los colores y sus efectos psicológicos que habían iniciado Humbert de Superville con sus "Ensayos sobre los signos incondicionales del arte" (1827) y Blanc con su "Gramática del Diseño" (1867). La presencia de Kandinsky en la Bauhaus tenía una doble finalidad: enseñar a pensar de manera lógica y proveer de las nociones teóricas necesarias, logradas gracias a la "necesidad interior", concepto indefinible en el que se apoya una metodología tan arbitraria como cualquier método académico.

\footnotetext{
Kandinsky, W. "pinto y línea sobre el plano", Ed. Barral, 1970. p. 14.

${ }^{26}$ Op. cit. p. 15

${ }^{27}$ Op. cit. p. 21
} 
Después de la experiencia de la Bauhaus, Kandinsky siguió pintando en Francia, donde pasó sus últimos diez años, empeñado en acomodar esa geometría desobediente, en poner orden en aquel mundo de protozoarios y amebas, que enmarcados en cuadrados o en círculos parecían encerrados en las vitrinas de ese museo deshistorizado que proyectó en Rusia y que no tuvo éxito.

Para concluir podríamos decir que el arte de Kandinsky encuentra su explicación en la teoría de la Einfuihlung (empatía) de Worringer publicada en su famoso libro "Abstracción y naturaleza" en 1908. Dora Valier ${ }^{28}$ explica el significado de este término utilizado por Worringer: "La empatía tiene lugar cuando el entendimiento ha tomado las riendas sobre el instinto. El instinto es el miedo, la angustia frente a la realidad del mundo. El alcance de la empatía tiene por condición una relación de confianza total y feliz entre el hombre y los fenómenos exteriores, mientras la abstracción es, por el contrario, la consecuencia de una grande inquietud interior en el hombre, provocada por los fenómenos del mundo exterior y que corresponde, en el dominio de la religión, a una fuerte coloración trascendental de la imaginación". El miedo, declarado en algunos pasajes de "De lo espiritual ...", encontró su forma en las abstracciones, cada vez más extremadas, a partir de la primera década del siglo.

"De lo espiritual en el arte", escrito en Alemania, fue la respuesta a las tendencias pictóricas de ese país, donde se habían desarrollado las líneas del realismo, impresionismo y simbolismo que se acomodaban a una sociedad burguesa y materialista. En Munich de esos años puede haber tenido cierto efecto vanguardista, pero en adelante y frente a la carrera vertiginosa de las vanguardias más radicales (italiana y rusa), la propuesta de Kandinsky se queda en la inconformidad obediente de los movimientos secesionistas, tanto alemán como vienés, propugnando más bien una especie de aristocracia del espíritu, que la ruptura del sistema artístico tradicional.

Como Kandinsky es un teósofo declarado, se puede también explicar su obra en clave teosófica. "La teosofía tiene por finalidad la unión con Dios, recomendando reglas de vida que garanticen el triunfo del espíritu, pero este triunfo en lugar de rechazar la naturaleza la abarca, ya que la tarea de la teosofía es enunciar las leyes secretas del universo" 29 . Así esta naturaleza, especie de fondo antediluviano donde se desarrolla la vida microscópica, evoluciona hacia la geometría ordenadora. Del miedo instintivo se pasa a la razón; pero también se puede decir, de una sociedad caótica se camina hacia la sociedad ordenada y feliz del futuro. ¿Pensaba Kandinsky en esta sociedad cuando comenzó la revolución rusa? Puede haber pensado en la utopía teosófica, no lo sabemos. Lo cierto es que el fenómeno ruso le pasa delante y el no lo entiende: no hay "resonancia interior" en medio del fragor de esos años turbulentos.

El teósofo termina adaptándose a las propuestas del desarrollo industrial y gracias a la experiencia de la Bauhaus, la naturaleza caótica, motivo de su miedo, se ordena por la acción de un nuevo poder, la industria, con la que, la escuela Bauhaus y el artista, han hecho las paces definitivamente.

\footnotetext{
${ }^{28}$ Valier, Dora. Op. cit. p. 26

${ }^{29}$ Op. cit. p. 12
} 